\title{
Review: rehabilitation improves exercise capacity and alleviates shortness of breath in chronic obstructive pulmonary disease
}

Salman GF, Mosier MC, Beasley BW, et al. Rehabilitation for patients with chronic obstructive pulmonary disease: meta-analysis of randomized controlled trials. J Gen Intern Med 2003;18:213-21.

\section{$Q$ In patients with chronic obstructive pulmonary disease (COPD), does rehabilitation (extremity or respiratory muscle exercise) increase exercise capacity and alleviate shortness of breath?}

\section{METHODS}

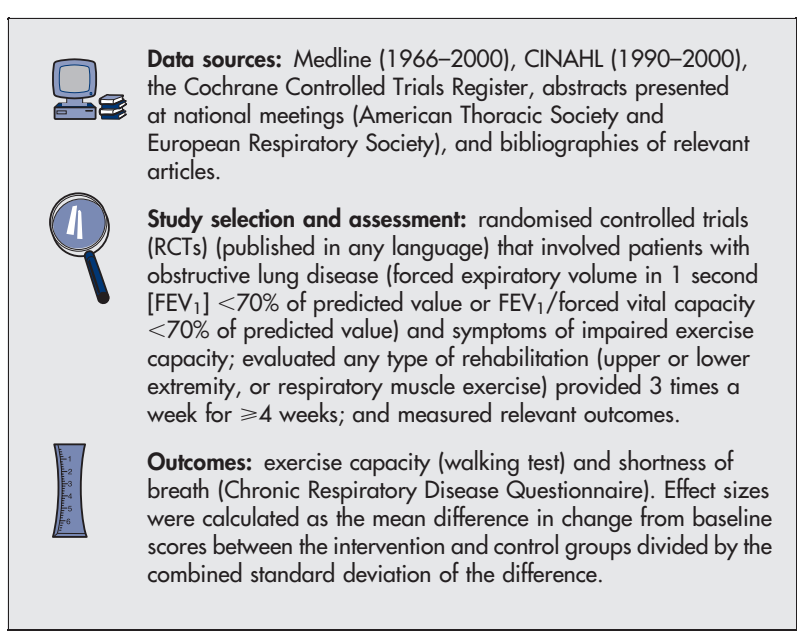

\section{MAIN RESULTS}

20 RCTs $(\mathrm{n}=999)$ met the selection criteria. Meta-analyses were done using a random effects model. Improvement from baseline in exercise capacity was greater in the rehabilitation group than in the control group (table). Alleviation of shortness of breath was greater in the rehabilitation groups than in the control groups (table). Subgroup analysis of RCTs that evaluated at least lower extremity training also showed that improvement in exercise capacity (18 RCTs) and alleviation of shortness of breath (11 RCTs) were greater in the rehabilitation group than the control group ( $p$ values $<0.05$ ). Subgroup analysis of RCTs that evaluated only respiratory muscle training showed that the groups did not differ for any outcomes.
For correspondence: Dr G F Salman, Austin Diagnostic Clinic, Austin, TX, USA.gsalman@addlinic.com

Sources of funding: no external funding.

\section{CONCLUSION}

In patients with chronic obstructive pulmonary disease, rehabilitation (using at least lower extremity muscle exercise) improves exercise capacity and alleviates shortness of breath.

\section{Commentary}

The meta-analysis by Salman et al used an extensive search strategy to identify studies and searched a wide range of sources. Sensitivity analyses were done to determine whether study size, quality, or the different models for aggregating studies (ie, fixed $v$ random effects models) influenced the outcomes. The outcomes proved robust to these analyses.

Patients with COPD had improved dyspnoea and exercise capacity after pulmonary rehabilitation. A previous meta-analysis reached a similar conclusion. ${ }^{1}$ However, the review by Salman et al has added value for clinicians because it also analysed the effects of pulmonary rehabilitation by disease severity, type of exercise programme, and length of programme. The criteria used for classification of COPD are widely recognised, and the rehabilitation programmes are typical to those generally used. Thus, the findings of this review should be broadly applicable. The authors concluded that effective programmes would use "at least" lower extremity exercise and that rehabilitation programmes for severe COPD should be $\geqslant 6$ months long. Most programmes included upper extremity exercise in tandem with lower extremity exercise, and therefore no judgments could be made about the effects of purely upper extremity or respiratory exercise.

Upper extremity exercise can be difficult for patients with COPD, and therefore at least lower extremity exercises should be prescribed. Future studies should investigate whether upper extremity exercise or respiratory exercise is beneficial. In addition, studies should investigate the effect of rehabilitation on function of patients with COPD in daily life. There is a paucity of research on this question.

Judith L Reishtein, RN, PhD School of Nursing, University of Pennsylvania Philadelphia, Pennsylvania, USA

1 Lacasse Y, Brosseau L, Milne S, et al. Pulmonary rehabilitation for chronic obstructive pulmonary disease. Cochrane Database Syst Rev 2003;(4):CD003793.

Rehabilitation (upper or lower extremity, or respiratory muscle exercise) $v$ control in chronic obstructive pulmonary disease*

\begin{tabular}{|c|c|c|c|}
\hline Outcomes at 8 weeks to 6 months & Number of RCTs (n) & Mean effect size $(95 \% \mathrm{Cl})$ & $\begin{array}{l}\text { Percentage of control patients with worse } \\
\text { outcome }(\mathrm{Cl}) \dagger\end{array}$ \\
\hline $\begin{array}{l}\text { Exercise capacity } \\
\text { Shortness of breath }\end{array}$ & $\begin{array}{l}20(979) \\
12(723)\end{array}$ & $\begin{array}{l}0.71(0.43 \text { to } 0.99) \\
0.62(0.26 \text { to } 0.91)\end{array}$ & $\begin{array}{l}76 \%(67 \text { to } 84) \\
73 \%(60 \text { to } 82)\end{array}$ \\
\hline
\end{tabular}

${ }^{*} \mathrm{RCTs}=$ randomised controlled trials. Cl defined in glossary.

†Compared with the average patient in the treatment group. 